\title{
Positioning family planning quality within health financing for UHC: Connecting the discourse
}

\author{
Gabrielle Appleford \\ Saumya RamaRao \\ Population Council \\ Benjamin Bellows \\ Population Council \\ Leah Jarvis \\ Population Council
}

Follow this and additional works at: https://knowledgecommons.popcouncil.org/departments_sbsr-rh

Part of the Demography, Population, and Ecology Commons, Family, Life Course, and Society Commons, International Public Health Commons, and the Women's Health Commons How does access to this work benefit you? Let us know!

\section{Recommended Citation}

Appleford, Gabrielle, Saumya RamaRao, Benjamin Bellows, and Leah Jarvis. 2019. "Positioning family planning quality within health financing for UHC: Connecting the discourse." New York: Population Council. 


\section{POSITIONING FAMILY PLANNING QUALITY WITHIN HEALTH FINANCING FOR UHC: CONNECTING THE DISCOURSE}

\section{INTRODUCTION}

Financing is a major challenge and concern for the future of the delivery of voluntary family planning (FP) services to clients, particularly in low- and middle-income countries with high unmet need and limited method choice. As countries commit to universal health coverage $(\mathrm{UHC})$, it is crucial that UHC schemes include FP and other reproductive health $(\mathrm{RH})$ services. Strategic purchasing of quality FP services from public and private - including for profit and not-for-profit - healthcare providers could accelerate progress toward UHC.

It is increasingly recognized that the FP2020 goals will not be met without adequate attention to quality; and that a sustained focus on quality of care requires financing at the policy and program levels. While the importance of sustainable financing may be recognized, the 'how' of financing for quality FP within the context of UHC is not well understood.

This brief targets the 'bridge' constituency that is coalescing between the health financing and FP communities of practice around a shared interest in making access to health services universal. With this brief, we aim to identify opportunities for the FP community of practice to advocate for the inclusion of quality, voluntary, and equitable FP services within UHC and health financing discussions.

\section{METHODOLOGY AND OUTLINE}

This technical brief drew on selected published and grey literature on quality of care, FP and UHC. The technical brief is divided into four sections:

- Section 1: outlines the quality and the UHC agenda, their grounding in rights, challenges with measurement, and how financing arrangements may affect quality

- Section 2: outlines quality and FP, its client-oriented genesis, challenges with routine measurement, and efforts to analyze FP performance within financing arrangements

- Section 3: outlines quality and strategic purchasing for FP, using the five Ps analytical framework to illustrate implications for the provision of quality FP services

- Section 4: summarizes three important aspects of strategic purchasing for FP quality - the use of FP data and evidence to inform purchasing, FP quality by design and FP quality by implementation within purchasing schemes 


\section{QUALITY AND UHC}

Quality and sustainable financing of UHC are interlinked. Quality underpins sustainable financing as public support for - and the sustainability of - financing of UHC may be undermined by poor quality. Quality also underpins UHC as health services must be of high enough quality in order to improve health (Starrs et al, 2018). This is defined as effective coverage, a modified measure of population coverage, based on functional access to quality services (Shengelia et al, 2005). While some lower- and middle-income countries (LMICs) have achieved UHC, they have not achieved effective coverage. ${ }^{1}$ In Mexico, for example, where substantial progress toward UHC has been achieved over time, effective or quality-corrected coverage of health services remains relatively low and uneven across states (Lozano et al, 2006, in Akachia and Kruk, 2017).

\section{UHC quality objectives are grounded in rights and} people-centered care. Many LMICs constitutionally guarantee the right to health care for their citizens. Furthermore, many LMICs espouse integrated people-centered health services (IPCHS). This approach, adopted by WHO member states in $2016,{ }^{2}$ is intended to provide services that are of better quality, are financially sustainable and more responsive to individuals and communities (Box 1). While aspirational in many contexts, IPCHS signals intent to reorient service delivery and health financing away from hospital-based, disease-based and "silo" curative care models, as these run counter to the provision of universal, equitable, high-quality and financially sustainable care (WHO, 2016). Ensuring that the UHC mandate is met requires backing the policy framework with sustainable financing.

While quality is integral to UHC, its measurement is 'inadequate to the task' (Akachia and Kruk, 2017). Ideally structure, process and outcomes measures, as defined by Donabedian's theory of quality (1988), would be tracked and linked. However, this does not tend to occur in practice. Partly this is due to a lack of consensus on how to measure, with many tools of 'substantial variation in their content and comprehensiveness' in use (Akachia and Kruk, 2017). Most of these address 'structure'. 'Process,' such as interpersonal care and the patient experience, and 'outcomes' linked to quality of care provided in the health system, are rarely measured. This is partly due to cost and the budget constraints under which ministries of health operate. Prioritization of quality is also a factor, with trade-offs made between ensuring effective service coverage and minimum quality standards (Akachia and Kruk, 2017).

\section{BOX 1. Approach to people-centred care}

"All people have equal access to quality health

services that are co-produced in a way that meets their

life course needs, are coordinated across the continuum

of care, and are comprehensive, safe, effective, timely,

efficient and acceptable; and all carers are motivated,

skilled and operate in a supportive environment".

Source: Framework on integrated, people-centred health services, page 4. WHO, 2016

Financing arrangements may work at cross purposes with UHC quality objectives. While health policies may set out explicit standards of quality, these may be mediated through financing arrangements, which may work at cross purposes to people-centered quality care. For example, these may influence how institutional providers (facilities and health systems) and individual healthcare workers provide health services with implications for quality (McLoughlin and Leatherman, 2003). Health financing arrangements may also generate additional costs, through the underuse, overuse, and misuse of interventions and services (McLoughlin and Leatherman, 2003).

\section{QUALITY AND FP}

FP, like UHC, is grounded in client rights and people-centered care. Commencing in 1994 with the International Conference on Population and Development (ICPD) in Cairo, the rhetoric of population control was replaced with individual rights to dignity, sexual and reproductive health, and the right to plan one's family (UNFPA, 2014). This spurred a sexual and reproductive health and rights (SRHR) movement that increasingly placed the user at the center of service delivery, with a focus on choice, equity, and quality as rights. These elements feature in the Quality of Care Framework, first developed by Bruce (1990) and updated by Jain and Hardee 2018 (Box 2). The ‘Bruce-Jain' framework, as it is commonly known, and the updated Jain-Hardee version, feature structure, process and outcome elements, in line with the Donabedian theory of quality. Box 2 provides a description of each of the six process elements in the framework. This framework, well accepted by the FP community, is referenced in many program settings and has been employed to design, develop and influence new models of client-centered FP. 
FIGURE 1. Bruce-Jain FP quality of care framework

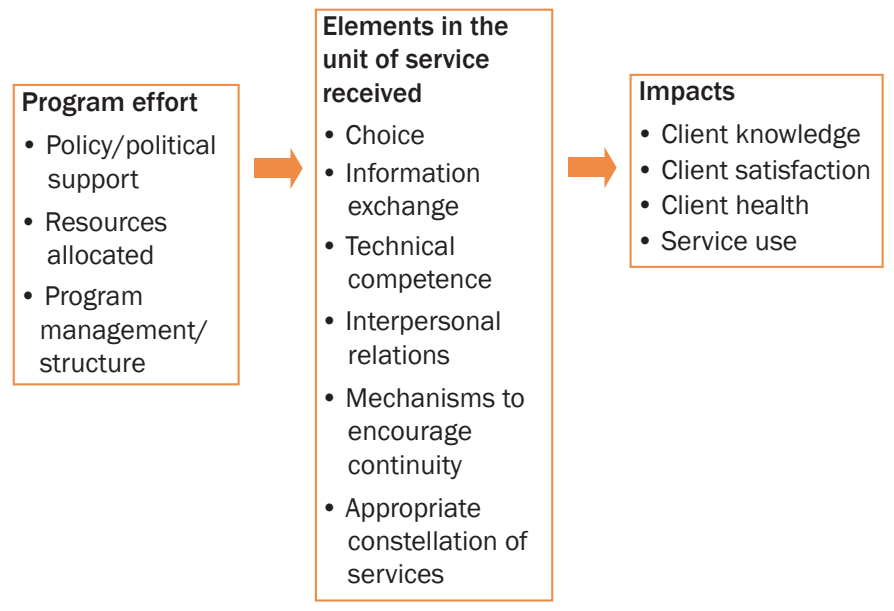

Source: Based on Jain and Hardee, 2018

While quality is integral to FP, there is less consensus on its routine measurement. There are many tools to assess the quality of FP services, however, there is lack of agreement on their routine use (Sprockett 2017). Recent studies have validated quality measures appropriate for routine reporting in FP service delivery settings, finding that higher values on the FP quality measures were associated with increased contraceptive use and reduced discontinuation (Jain et al, 2013; Jain and Winfrey, 2017; Chakraborty et al, 2019; Jain et al, 2019; Holt et al, 2019). While the evidence and the validated metrics are promising, measurement of rights such as client autonomy in service delivery settings can be further improved (Bertrand et al, 2014; Cole et al., 2019). Where standard indicators from readily available data sources exist, there is a need to strengthen their adoption. Where standard indicators are lacking, new metrics are needed, to foster greater consensus on routine measurement of FP quality.

There have been some recent efforts to analyze FP 'performance' within health financing mechanisms. This has included systematic reviews of specific financing models, such as community financing and community-based health insurance (Karra et al, 2016), conditional and unconditional cash transfers (Khan et al, 2016), introducing, removing, or changing OOP costs or user fees (Korachais et al, 2016), results-based financing (Blacklock et al, 2016), performance-based incentives (Bellows et al, 2014), and social protection programs that provide a voucher subsidy (Bellows et al, 2016). These studies and others have not specifically looked at the quality of FP provided under such schemes using the Bruce-Jain framework or related elements. However, out of these and other efforts, a community
BOX 2. Updated Bruce-Jain process elements of quality of care in FP

Choice: Be able to offer a range of contraceptive methods

Information exchange: The provision of information to clients and the solicitation of information and preferences from clients

Technical competence: Availability of trained providers competent in sterilization operation and/or in insertion and removal of reversible clinical methods (e.g., IUD, implant) as well as to ensure safety and compliance with infection prevention practices in delivering these services

Interpersonal relations: Relations that uphold dignity, respect, privacy, and confidentiality

Mechanisms to encourage continuity: Information exchange should include follow-up requirements and guidance on the possibility of switching the method, provider, or service outlet

Appropriate constellation of services: Integration of FP with other RH services such as safe abortion/post-abortion care; testing and treatment for sexually transmitted diseases, including HIV; and gender-based violence services

Source: Based on Jain and Hardee (2018)

of practice and research agenda have coalesced around FP measurement, including aspects of client-centeredness and rights, within specific purchasing instruments. ${ }^{3}$

\section{QUALITY AND FP PURCHASING}

There are a variety of approaches to purchasing FP services, each with potential implications for quality as outlined in the Bruce-Jain framework. When used strategically, these may enhance equity in the distribution of resources, increase efficiency, manage expenditure growth and promote quality in health service delivery (WHO, 2017). Strategic purchasing is intended to be an active approach, a 'continuous search for the best ways to maximize health system performance by deciding which interventions should be purchased, how, and from whom' (RESYST, 2014). Purchasing schemes, procuring on behalf of the

\footnotetext{
${ }^{3}$ See, for example The Collectivity https://www.thecollectivity.org/en/projects/right-based-approach.
} 
TABLE 1. 5P and Bruce-Jain frameworks for FP

\begin{tabular}{|c|c|c|c|}
\hline Purchasing domains & Purchasing elements & FP considerations & $\begin{array}{l}\text { Bruce and Jain } \\
\text { framework }\end{array}$ \\
\hline $\begin{array}{l}\text { Polities: Why to } \\
\text { purchase (rationale } \\
\text { and institutional } \\
\text { arrangements) }\end{array}$ & $\begin{array}{ll}\text { - } & \text { Political commitment } \\
\text { - } & \text { mentitutional arrange- } \\
\text { - } & \text { Purchaser alignment } \\
\text { (across mechanisms) } \\
\text { - } \text { Monitoring and ac- } \\
\text { countability } \\
\text { - Performance } \\
\text { management }\end{array}$ & $\begin{array}{l}\text { - Societal benefits } \\
\text { (SRHR, gender equality, } \\
\text { public health impact) } \\
\text { Economic benefits } \\
\text { (women's participation } \\
\text { in the labor force and } \\
\text { demographic dividend) } \\
\text { - } \quad \text { ormative environment } \\
\text { and ability to realize } \\
\text { rights for FP } \\
\text { Stewardship and } \\
\text { ownership (e.g. } \\
\text { government and } \\
\text { donors, central and } \\
\text { decentralized) } \\
\text { Fragmentation and } \\
\text { adequacy of financing } \\
\text { (horizontal and vertical } \\
\text { coherence) }\end{array}$ & $\begin{array}{ll}\text { - } & \text { Policy/political } \\
\text { support } \\
\text { - } \\
\text { Resource } \\
\text { allocated } \\
\text { - Program } \\
\text { management/ } \\
\text { structure }\end{array}$ \\
\hline $\begin{array}{l}\text { People: For whom to } \\
\text { purchase }\end{array}$ & $\begin{array}{ll}\text { - } & \text { Defined target } \\
& \text { clientele } \\
\text { - } & \text { Clientele awareness } \\
\text { - } & \text { Community and } \\
\text { society engagement }\end{array}$ & $\begin{array}{ll}\text { - } & \text { Unmet need } \\
\text { - } & \text { Equity (e.g. poor } \\
\text { women and men, } \\
\text { adolescents) } \\
\text { - Client continued use } \\
\text { (through method } \\
\text { choice) } \\
\text { - Financial barriers/ } \\
\text { out-of-pocket } \\
\text { expenditure }\end{array}$ & \\
\hline $\begin{array}{l}\text { Package: What to } \\
\text { purchase }\end{array}$ & 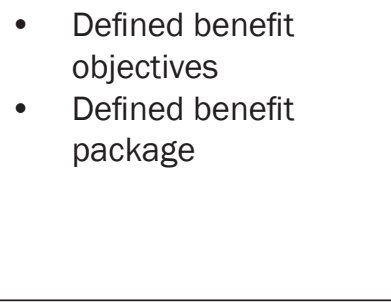 & $\begin{array}{l}\text { - } \quad \text { Broad method mix to } \\
\text { improve choice, enable } \\
\text { switching, and reduce } \\
\text { discontinuation } \\
\text { - FP integration into } \\
\text { RMNCAH continuum/ } \\
\text { packages }\end{array}$ & 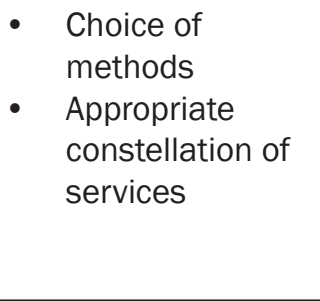 \\
\hline $\begin{array}{l}\text { Provider: From whom to } \\
\text { purchase }\end{array}$ & $\begin{array}{ll}\text { - } & \text { Contracting } \\
\text { - } & \text { Accreditation } \\
\text { - } & \text { Integration (e.g. of } \\
\text { public and private } \\
\text { providers) }\end{array}$ & $\begin{array}{l}\text { - Physical access/choice } \\
\text { of outlet } \\
\text { - } \text { Minimum quality } \\
\text { standards } \\
\text { - } \quad \text { Integration of the } \\
\text { private sector } \\
\text { - Client realization of FP } \\
\text { rights }\end{array}$ & $\begin{array}{ll}\text { - } & \text { Technical } \\
\text { - } & \text { Informpetence } \\
\text { - } & \text { to clients } \\
\text { Interpersonal } \\
\text { relations } \\
\text { - Follow up/ } \\
\text { continuity } \\
\text { mechanisms } \\
\end{array}$ \\
\hline $\begin{array}{l}\text { Payment: How to } \\
\text { purchase }\end{array}$ & $\begin{array}{ll}\text { - } & \text { Payment rates } \\
\text { - } & \text { Payment methods } \\
\text { - } & \text { Provider autonomy } \\
\text { - } & \text { Qualims processing } \\
& \text { (data ansurance } \\
\text { (dinical) }\end{array}$ & $\begin{array}{ll}\text { - } & \text { Likelihood of being } \\
\text { offered choice of FP } \\
\text { method (e.g. provider } \\
\text { behavior) } \\
\text { - } \quad \text { Efficiency and quality } \\
\text { - } & \text { Regulatory and public } \\
\text { financial management }\end{array}$ & \\
\hline
\end{tabular}


health system, may include national health insurance, voucher programs, results-based financing and input-based budgets or a combination thereof. To illustrate how purchasing elements may support or constrain FP quality, the 5P framework (Appleford and RamRao, 2018) (Table 1) has been overlaid to the Bruce-Jain framework. Following the table, we describe how the different elements of FP purchasing may influence quality of care with particular focus on "for whom to purchase", "what to purchase", "from whom to purchase" and "how to purchase."

\section{People: for whom to purchase}

\section{For whom to purchase has implications for FP access.}

These considerations do not feature explicitly in the BruceJain framework but are reflected in 'program effort' (see Figure 1), if this is directed towards equity of access. Progress toward UHC is intended to remove financial barriers to access to quality health services. However, FP financial barriers for women and girls may not be recognized or prioritized within UHC schemes, even by the FP community, given other supply- and demand-side barriers (Lie et al, 2015). It is estimated that out-of-pocket (OOP) payments comprise nearly half (49\%) of the costs of reproductive, maternal, neonatal, and children's healthcare (Lie et al, 2015) and will account for most of the financing for FP products over the next three years (RHSC, 2018). Financing through OOP for FP may not be viewed as catastrophic or a financial hardship for women and girls but may result in unplanned pregnancy and recourse to unsafe abortion, with potentially catastrophic consequences for the individual and her family; furthermore the health system will bear costs due to the management of mistimed or unintended pregnancies.

FP choice may reflect price rather than preference. This extends to decisions to seek FP services, from whom, and what methods to use. A study by Ugaz et al (2016) found that, in 17 of 30 countries, a greater proportion of poorer women used short-acting methods over long-acting methods than wealthier women, suggesting that financial barriers may suppress choice. For adolescents, cost may deter them from accessing health services altogether, more so than adults. This may be due to their limited capacity to access services independent of their parents, and their limited access to cash, either their own or that of their family (Waddington and Sambo, 2015). The WHO global consultation on adolescents indicated that very few (6\%) adolescents pay OOP for health services with many (45\%) reporting that their parents and/or family members were the principal payers of their healthcare costs (WHO, 2019), which are unlikely to include FP or other SRH services. When financial barriers are removed, an individual may be able to act upon their preference to both seek and choose a FP method. However, it is recognised that other barriers may exist and intersect with financial ones.

\section{Package: what to purchase}

What to purchase has implications for FP choice and an appropriate constellation of services. While governments often prioritize essential health services in benefits packages, this does not always include FP. Research by Eldridge and Appleford (2016) found that only six of 14 government-sponsored health insurance schemes in USAID FP priority countries included FP in their benefit package (no information was provided on constellation of services). Service exemption schemes for maternal and child health $(\mathrm{MCH})$, such as those in Sahelian countries, may also fail to include FP as part of a continuum of care (Appleford and Camara, 2018; Mazzilli et al, 2016). Even when FP is included in a benefits package or service exemption scheme, this may not translate to provision. A seven-country study of health insurance schemes (Ross et al, 2018) concluded that despite the formal inclusion of FP services in the national benefits packages examined, actual integration of these services faced challenges, with implications for the availability of FP services in practice. A study in India also found that use of FP under the national health insurance scheme was low, estimated at $2 \%$, with poorer families less likely to know of its inclusion (Mozumdar et al, 2019).

\section{The FP community may conflate FP inclusion in benefits} packages with choice. However, this may not account for user preference in outlets or differential requirements of FP methods. For example, non-clinical outlets, such as pharmacies or shops may be preferred by some users, who desire methods, such as condoms and emergency contraception, that does not require visiting a medical facility (Bertrand et al, 2014) and prefer a more anonymized, less interpersonal transaction. Long-acting reversible contraception (LARCs) on the other hand may benefit from explicit inclusion in a benefits package, given that these methods require a clinical setting and have additional competency and consumable requirements for their delivery. These differences may not be reflected within the global FP community, which may advocate for equal treatment of all FP methods within benefits packages, without a more nuanced view of requirements.

\section{Payment: how to purchase}

How to purchase within UHC schemes has implications for service quality. This is an important determinant of whether and how well services are provided. This includes more observable quality measures, such as technical competence and follow up/continuity mechanisms, as well as less observable quality measures such as interactions related to information given to clients and interpersonal relations. 
Payment mechanisms can influence the extent to which individuals can genuinely choose the FP method of their choice (Holtz and Sarker, 2018). Increasingly, LMICs are experimenting with different payment approaches and may blend two or more payment mechanisms For example, in Kenya, FP is included under capitation for short-term and long-acting methods and under fee-for-service for permanent methods within the National Hospital Insurance Fund (NHIF). The NHIF is implemented in public facilities where line item budgets cater for FP inputs such as health worker time and commodities and private facilities where there is no budget support.

A selection of payment mechanisms is featured to demonstrate their potential influence on FP quality. However, ideally performance of individual payment mechanisms would be considered holistically in a mixed provider payment system (Mclsaac, 2018).

\section{Line item budgets}

Family planning services have historically been financed using input-based methods. These input-based methods use a salary schedule for individual healthcare providers, based on their cadre, qualifications, and other factors. If providers are compensated regardless of service volume, they are free to spend as much time as needed with each patient and to tailor their services to the needs of the individual, potentially optimizing the information exchange. However, lacking any incentive toward service provision and quality, unmotivated providers may feel disinclined to offer complicated or expensive methods or procedures, such as LARCs or permanent methods.

Fee for service

Fee-for-service payments may create diverse financial incentives for providers to deliver "more, less, or different services" (Holtz and Sarker, 2018). Fee-for-service may be the most precise way to pay for actual services and can be used to encourage delivery of priority services (Holtz and Sarker, 2018). This may have the opposite effect of input-based payments, such as a health worker salary, and influence providers to perform services that require greater clinical skills, consumables and counseling. While this form of payment may improve the offer of LARCs and permanent methods, there are concerns within the FP community that this may result in over provision. However, a best practice guidance suggests that differential payment of FP methods such as LARCs is appropriate, if this is in line with reimbursement rates for other services (Eichler, 2018).

\section{Results-based payments}

Results- and performance-based financing (PBF) 4 is purchasing of health services linked to a goal or result. When goals are linked to quality, efficiency, or positive health outcomes, this may be a strategy for improving quality of services, although evidence of its impact on quality is inconclusive (Akachia and Kruk, 2017). If goals are linked to quantity of services provided, this may disincentivize quality by emphasizing the numbers of clients served with FP. In practice, many of these payment mechanisms have a quantity-based result and a quality-based modifier (Cole et al, 2019). A recent multi-country review (Cole et al, 2019) sought to map the extent to which PBF reflected quality, informed choice and volunteerism, using the principles of the Bruce-Jain framework. This review found 452 FP-related indicators used in PBF schemes, 57 quantity-based performance indicators and 395 questions to assess the quality of FP services (Cole et al, 2019). The review concluded that rights elements were not uniformly represented and a more systematic approach to rights-based implementation of FP services in PBF programs is needed.

Specific indicators, such as new users, may also run counter to Bruce-Jain quality elements. Many PBF schemes count new FP users as a primary measure. However, this measure can have multiple definitions including first-time user, new to the provider (e.g., provider-changer), new to the method (e.g., switching methods), not recently using a method (e.g., lapsed user), and even additional user (Dasgupta et al. 2017). Irrespective of definition, a focus on new users has been associated with less diverse method mix, greater provider bias, or more frequent commodity stock-outs and may reflect users having limited information and fewer options (RamaRao and Jain 2015). PBF schemes may also focus on method-specific indicators, linked with higher-level impact measures such as the relative effectiveness of specific methods or a desire to remove price as a barrier to consumer choice (Cole et al, 2019). This may be an important PBF objective in contexts where there is low overall utilization of modern FP, high reliance on short-term methods, such as condoms, and financial barriers to method choice such as LARCS.

\footnotetext{
${ }^{4}$ Performance-based financing (PBF) programs are considered a specific subset of RBF initiatives and are distinguished by a focus on monetary incentives to healthcare providers for achieving agreed performance measure under certain conditions.
} 


\section{Capitation}

Capitation is a payment arrangement for health care service providers that pays a set amount for each enrolled person assigned to them, per period of time, whether or not that person seeks care. It is a form of payment that places the provider, and not the purchaser, at risk for the amount and quality of services used (Holtz and Sarker, 2018). As a prospective payment made to providers on a per-person, per period basis for a defined set of services, capitation is thought to create better alignment of financial incentives between healthcare purchasers and providers. It is well suited to pay for predictable and commonly used services. It is less well suited for the full range of FP services unless this is explicitly rewarded. This mode of payment forces providers and facilities to work within a budget, which can incentivize more efficient care, prioritizing those with the greatest needs. However, this also may influence facilities to effectively ration quality, by minimizing the expense spent on each patient/client. Given this, the rate of capitation matters to quality - in theory, the higher the rate, the more likely a provider receives sufficient revenue to provide needed services, with good quality. Conversely, a low rate of capitation may compromise quality.

\section{Capitation may act as a disincentive for the provision of} resource-intensive FP methods. When considering a voluntary service such as FP that is predominantly used by women, a provider could attract a mix of patients who use many FP services, yet receives the same capitation payment as another provider who provides few or no FP services. Additionally, if FP services are included in a capitation payment for a set of PHC services, all other things held equal, providers would have a financial incentive to provide short-acting methods since those methods are the most efficient (e.g. quick and cheap) to provide. This is one argument for "carving out" FP from capitation payments for primary care and paying for it on a fee-for-service basis (whether with case rates or at the service level).

\section{Provider: from whom to purchase}

\section{‘Healthy competition' through client choice of provider is} also an important aspect of quality. This may allow women and couples to select providers that have higher client perceptions of quality, such as short waiting times or more informative and interpersonal interactions with clients. While choice of provider is not explicit in the Bruce-Jain framework, it is implicit in framework impacts as it may be associated with greater client satisfaction, acceptance and continuation of contraception. According to a recent study, the private sector provides $37 \%$ of FP services globally, making a significant contribution to access; of this share, over half (54\%) of FP services are provided by medical providers, $36 \%$ by specialized drug sellers, and $6 \%$ by retailers
(Campbell et al, 2015 in Holtz and Sarker, 2018). Women also select providers based on OOP cost; clients may choose a private provider for short-term methods that are more affordable but seek more expensive methods such as LAPM from public providers, where the service may be free or nearly free for the consumer (Ugaz et al. 2013).

\section{BRINGING IT ALL TOGETHER}

Service quality should inform resource allocation decisions and strategic purchasing arrangements. This should be supported by available data and evidence, even though not all FP quality elements from the Bruce-Jain framework may be represented. Some process quality elements, such as interpersonal care and client experience, are difficult to routinely measure, and thwart quality measurement in UHC more broadly. Given this, effort may be better placed on a normative environment for FP quality and rights evidenced through political commitment, national stewardship and ownership of FP programs (this equates to 'program effort' in the Bruce-Jain framework). Situating FP service quality within broader efforts to achieve and measure effective coverage of UHC is recommended.

The FP community should advocate for FP 'quality by design' within purchasing strategies. This would shift attention to the design of purchasing strategies and their effects on FP process elements in the Bruce-Jain framework. At present, FP quality is addressed as service units in the Bruce-Jain framework, and may benefit from a broader systems lens. Quality by design could include use of purchasing metrics that reduce risk of missed opportunities and promote the inclusion of quality FP within a continuum of care. For example, FP could be rewarded within antenatal and postnatal care as part of a quality modifier to PBF schemes. This would better align with UHC quality and health systems objectives of integrated people-centered care.

The FP community should ensure that purchasing strategies support a client-oriented or rights-based approach to high quality services. The quality of FP services is determined by measuring service inputs, processes and outcomes. FP purchasing strategies may incentivize high quality but still fail to strengthen a rights-based approach. Implementing FP purchasing strategies from a rights-based perspective asks which policies will help to make the FP service universally accessible, acceptable, and available. Regardless of the purchasing strategy selected in a given context, the FP community of practice has an obligation to ensure that the purchasing strategy supports a rights-based approach to high quality FP services. 


\section{REFERENCES}

Akachia, Y. and M.E. Kruk. 2017. "Quality of care: measuring a neglected driver of improved health," Bulletin of the World Health Organisation 95 (6):465-472. doi: http://dx.doi. org/10.2471/BLT.16.180190.

Appleford, G. and S. RamaRao. 2018. Health financing and family planning in the context of Universal Health Care: Connecting the discourse in Kenya. Population Council, New York, USA.

Appleford, G. and S. Camara. 2018. Positioning family planning services within health financing and universal health care in the Sahel. Marie Stopes International, London, UK.

Eldridge, C. and G. Appleford. 2016. Scoping demand side financing schemes for family planning. Unpublished report. Avenir Health, Glastonbury, USA.

Bellows, N.M., I. Askew, and B. Bellows. 2014. Review of performance-based incentives in community-based family planning programmes. The journal of family planning and reproductive health care, pp.1-6. Available at: http://www. ncbi.nlm.nih.gov/pubmed/25037703

Bellows, B., C. Bulaya, S. Inambwae, C. L. Lissner, M. Ali, and A. Bajracharya. 2016. Family Planning Vouchers in Low- and Middle-Income Countries: A Systematic Review. Studies in Family Planning, 47(4), 357-370.

Bellows, N.M., I. Askew, and B. Bellows. 2015. "Review of performance-based incentives in community-based family planning programmes," The Journal of Family Planning and Reproductive Health Care, 41: 146-151. Available at: https:// srh.bmj.com/content/familyplanning/41/2/146.full.pdf.

Bertrand, J.T., T.M. Sullivan, E.A. Knowles, M.F. Zeeshan, and J.D. Shelton. 2014. "Contraceptive method skew and shifts in method mix In low- and middle-income countries," International Perspectives on Sexual and Reproductive Health, 40(3):144-153, doi: 10.1363/4014414.

Blacklock, C., E. MacPepple, S. Kunutsor, and S. Witter. 2016. "Paying for performance to improve the delivery and uptake of family planning in low- and middle-income countries: A systematic review," Studies in Family

Planning 47(4): 390-324.

Bruce, J. 1990. "Fundamental Elements of the Quality of Care: A Simple Framework," Studies in Family Planning 21(2):61-91.
Chakraborty N.M., K. Chang, B. Bellows, K.A. Grépin, W. Hameed, and A. Kalamar et al. 2019. "Association Between the Quality of Contraceptive Counseling and Method Continuation: Findings From a Prospective Cohort Study in Social Franchise Clinics in Pakistan," Global Health Science and Practice 7(1): 87-102.

Cole, M.S., V. Boydell, K. Hardee, and B. Bellows. 2019. “The extent to which performance-based financing programs' operations manuals reflect rights-based principles: Implications for family planning services." Global Health: Science and Practice, Vol. 7(2): 329-339.

Dasgupta, A., M. Weinberger, B. Bellows, and W. Browne. 2017. "New Users" Are Confusing Our Counting: Reaching Consensus on How to Measure "Additional Users" of Family Planning," Global Health: Science and Practice 5(1): 6-14.

Donabedian, A. 1988. "The quality of care. How can it be assessed?," JAMA. Sep 23-30 260(12):1743-8. doi: http:// dx.doi.org/10.1001/ jama.1988.03410120089033 PMID: 3045356 .

Eichler, R., J. Wright, B. Bellows, M. Cole, V. Boydell, and K. Hardee. 2018. Strategic purchasing to support voluntarism, informed choice, quality and accountability in family planning: Lessons from results-based financing. Health Finance \& Governance Project, Abt Associates Inc, Rockville, MD, USA.

Holt, K., I. Zavala, X. Quintero, D. Hessler, and A. Langer. 2019. “Development and Validation of the Client-Reported Quality of Contraceptive Counseling Scale to Measure Quality and Fulfillment of Rights in Family Planning Programs," Studies in Family Planning 50(2): 137-158.

Holtz, J. and I. Sarker. 2018. Integrating Family Planning into Universal Health Coverage Efforts. Abt Associates, Bethesda, MD, USA.

Jain, A., K. Aruldas, A. Mozumdar, E. Tobey, and R. Acharya. 2019. "Validation of Two Quality of Care Measures: Results from a Longitudinal Study of Reversible Contraceptive Users in India," Studies in Family Planning 50(2): 179-193.

Jain, A.K. and K. Hardee. 2018. "Revising the FP Quality of Care Framework in the Context of Rights-based Family Planning," Studies in Family Planning 49(2):171-179.

Jain, A.K., F. Obare, S. RamaRao, and I. Askew. 2013. "Reducing unmet need by supporting women with met need," International Perspective on Sexual and Reproductive Health 39(3): 133-141.

Jain, A.K. and W. Winfrey. 2017. "Contribution of Contraceptive Discontinuation to Unintended Births in 36 Developing Countries," Studies in Family Planning 48(3): 269-278. 
Karra, M., D. Canning, J. Hu, M. Ali, and C. Lissner. 2016. "Community-Based Financing of Family Planning in Developing Countries: A Systematic Review," Studies in Family Planning, 47(4): 325-339.

Khan, M.E., A. Hazra, A. Kant, \& M. Ali, 2016. “Conditional and Unconditional Cash Transfers to Improve Use of Contraception in Low- and Middle-Income Countries," Studies in Family Planning, 47(4): 371-383.

Korachais, C., E. Macouillard, and B. Meessen. 2016. "How user fees influence contraception in low and middle income countries: A systematic review," Studies in Family Planning 47(4): 341-356.

Lie, G.S., A.L. Soucat, and S. Basu, 2015. “Financing women's, children's, and adolescents' health," British Medical Journal 351:h4267.

Lozano R., et al, 2006, in Y. Akachia and M.E. Kruk. 2017. "Measuring a neglected driver of improved health," Bulletin of World Health Organization 95:465-472. doi: http://dx.doi. org/10.2471/BLT.16.180190.

Mathauer, I., E. Dale, and B. Meessen. 2017. Strategic purchasing for Universal Health Coverage: Key policy issues and questions. A summary from expert and practitioners' discussions. World Health Organization, Geneva.

Mazzili, C., G. Appleford, and M. Boxshall. 2016. MSl's Health Financing Assessments 2012-2015: What Did We Learn About UHC Financing and Contraception? Four 'Ps' Matter. Marie Stopes International. https://mariestopes.org/media/2689/ msi-4ps-matter-in-contraception-health-

financing.pdf.

Mclsaac, M., J. Kutzin, E. Daleb, and A. Soucat, 2018. “Results-based financing in health: From evidence to implementation," Bulletin of the World Health Organization 96(11):730730A. doi: http://dx.doi.org/10.2471/BLT.18.222968.

McLoughlin, V. and S. Leatherman. 2003. "Quality or financing: what drives design of the health care system?" Quality and Safety in Health Care 12(2):136-142.

Mozumdar, A., K. Aruldas, A. Jain and L. Reichenbach. 2018. “Understanding the use of India's National Health Insurance Scheme for family planning and reproductive health services in Uttar Pradesh," International Journal of Health Planning and Management 33(4):823-835.

RamaRao, S. and A.K. Jain. 2015. "Aligning Goals, Intents, and Performance Indicators in Family Planning Service Delivery," Studies in Family Planning 46(1): 97-104.
RESYST, 2014. What is Strategic Purchasing for Health? Topic Overview 4, Financing research theme; Resilient and Responsive Health Systems, London School of Hygiene and Tropical Medicine, London, UK. [Retrieved 3/11/2018].

Reproductive Health Supplies Coalition (RHSC). 2018. Global Contraceptive Commodity Gap Analysis 2018. RHSC: Brussels.

Ross, R., T. Fagan, and A. Dutta. 2018. Is Health Insurance Coverage Associated with Improved Family Planning Access? A Review of Household Survey Data from Seven FP2020 Countries. Health Policy Plus Project, Palladium, Washington, DC, USA.

Shengelia, B., A. Tandon, O.B. Adams, and C.J.L. Murray. 2005. "Access, utilization, quality, and effective coverage: an integrated conceptual framework and measurement strategy," Social Science and Medicine 61(1):97-109. http://www.ncbi.nIm. nih.gov/pubmed/15847965.

Sprockett, A., 2017. "Review of quality assessment tools for family planning programmes in low- and middle-income countries," Health Policy and Planning 32(2): 292-302. doi: 10.1093/heapol/czw123.

Starrs, A.M., A.C. Ezeh, G. Barker, A. Basu, J.T. Bertrand, R. Blum, et al. 2018. "Accelerate progress-sexual and reproductive health and rights for all: report of the Guttmacher-Lancet Commission," The Lancet Commissions 391(10140): 26422692. http://dx.doi.org/10.1016/S0140-6736(18)30293$9 \% 0 \mathrm{~A}$.

Ugaz J.I., M. Chatterji, J.N. Gribble, and K. Banke. 2016. “Is household wealth associated with use of long-acting reversible and permanent methods of contraception? A multi-country analysis," Global Health Science and Practice 4 (1): 43-54.

UNFPA (United Nations Population Fund). 1994. Programme of Action: Adopted at the International Conference on Population and Development, Cairo, 5-13 September 1994 (New York: UNFPA). https://www.unfpa.org/sites/default/files/event-pdf/ PoA_en.pdf.

Waddington, C., and C. Sambo. 2015. "Universal health care, health financing and adolescents," Bulletin of the World Health Organization 93(1):57-59. doi: 10.2471/BLT.14.139741.

World Health Organization (WHO). Towards adolescentresponsive health systems. https://www.who.int/ maternal_child_adolescent/topics/adolescence/seconddecade/en/ [accessed 18/3/2019].

World Health Organization (WHO). 2016. Framework on integrated people-centred health services. https://www.who.int/ servicedeliverysafety/areas/people-centred-care/en/ [accessed: 18/3/2019]. 


\section{ACKNOWLEDGMENTS}

We thank the David and Lucille Packard Foundation for their generous support which made this work possible. We also thank Anrudh Jain and Lethia Bernard for their review and insightful comments.

Suggested citation: Gabrielle Appleford, Saumya RamaRao, Ben Bellows, and Leah Jarvis, 2019. Positioning family planning quality within health financing for UHC:

Connecting the discourse. Population Council, New York. 